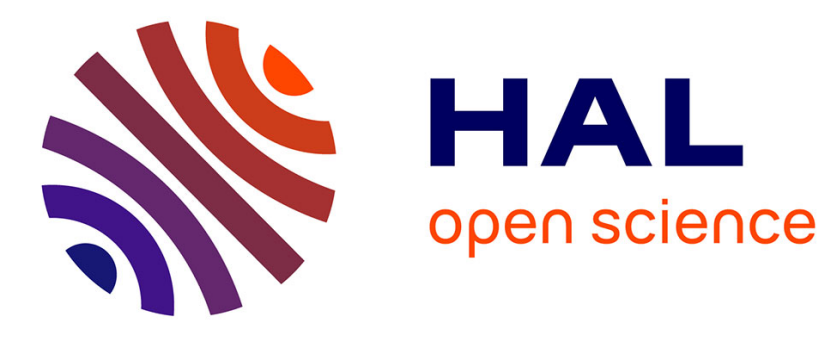

\title{
Towards Cloud in a PLM Context: A Proposal of Cloud Based Design and Manufacturing Methodology
}

\author{
Hussein Khlifi, Abhro Choudhury, Siddharth Sharma, Frederic Segonds, \\ Nicolas Maranzana, Damien Chasset, Vincent Frerebeau
}

\section{To cite this version:}

Hussein Khlifi, Abhro Choudhury, Siddharth Sharma, Frederic Segonds, Nicolas Maranzana, et al.. Towards Cloud in a PLM Context: A Proposal of Cloud Based Design and Manufacturing Methodology. 14th IFIP International Conference on Product Lifecycle Management (PLM), Jul 2017, Seville, Spain. pp.141-151, 10.1007/978-3-319-72905-3_13 . hal-01764151

\section{HAL Id: hal-01764151 \\ https://inria.hal.science/hal-01764151}

Submitted on 11 Apr 2018

HAL is a multi-disciplinary open access archive for the deposit and dissemination of scientific research documents, whether they are published or not. The documents may come from teaching and research institutions in France or abroad, or from public or private research centers.
L'archive ouverte pluridisciplinaire HAL, est destinée au dépôt et à la diffusion de documents scientifiques de niveau recherche, publiés ou non, émanant des établissements d'enseignement et de recherche français ou étrangers, des laboratoires publics ou privés.

\section{(c)(1)}

Distributed under a Creative Commons Attribution| 4.0 International License 


\title{
Towards cloud in a PLM context: A proposal of Cloud Based Design and Manufacturing methodology
}

\author{
Hussein Khlifi ${ }^{1,2}$, Abhro Choudhury ${ }^{1}$, Siddharth Sharma ${ }^{1}$, Frédéric Segonds ${ }^{1}$, Nicolas \\ Maranzana $^{1}$, Damien Chasset ${ }^{2}$, Vincent Frerebeau ${ }^{2}$ \\ ${ }^{1}$ Arts et Métiers, ParisTech, LCPI, 151 Boulevard de 1'Hôpital, 75013 Paris, France \\ ${ }^{2}$ Dassault Systèmes, 10 Rue Marcel Dassault, 78140 Vélizy Villacoublay, France \\ Hussein.khlifi@ensam.eu
}

\begin{abstract}
.
Product Lifecycle Management (PLM) integrates all the phases a product goes through from inception to its disposal but generally, the entire process of the product development and manufacturing is time-consuming even with the advent of Cloud-Based Design and Manufacturing (CBDM). With enormous growth in Information Technology (IT) and extensive growth in cloud infrastructure the option of design and manufacturing within a cloud service is a viable option for future. This paper proposes a cloud based collaborative atmosphere with real-time interaction between the product development and the realization phases making the experience of design and manufacturing more efficient. A much-optimized data flow among various stages of a Product Lifecycle has also been proposed reducing the complexity of the overall cycle. A case study using Additive Manufacturing (AM) has also been demonstrated which proves the feasibility of the proposed methodology. The findings of this paper will aid the adoption of CBDM in PLM industrial activities with reduced overall cost. It also aims at providing a paradigm shift to the present design and manufacturing methodology through a real-time collaborative space
\end{abstract}

Keywords: Cloud, Collaborative Design, PLM, Additive Manufacturing, Manufacturing.

\section{$1 \quad$ Introduction}

With the emergence of new advanced technologies and rapidly increasing competition for efficient product development, researchers and industry professionals are constantly looking for new innovations in the field of design and manufacturing. It has become a challenge to meet the dynamics of today's Marketplace in the manufacturing field as the product development processes are geographically spread out. In the research community of Cloud Based Design and Manufacturing ongoing debate constantly takes place on the key characteristics like cloud based design, communication among users, safety of data, data storage, and data management among others. Such discussions have now been answered with the developments of cloud based design 
and manufacturing. Efforts are now directed towards making advancements in the field of design and manufacturing by using IT tools \& PLM concepts. Few researchers are advancing in the field of developing a PLM paradigm in linking modular products between supplier and product developers [1], few others have extended their PLM research in the domains of Building information modeling by taking motivation and best practices from PLM by emphasizing more on information centric management approach in construction projects [2]. A revolutionary advancement of cloud services which now offers distributed network access, flexibility, availability on demand and pay per use services has certainly given push for applying cloud computing technology in the field of manufacturing. The intended idea of performing manufacturing on cloud has reached to such an extent that industries are forced to carry out operations in cloud rather than using the traditional methods.

Today's world is moving faster and is more connected than ever before due to globalization which has created new opportunities \& risks. Traditional methods lack the ability to allow users, who are geographically spread out to work in a collaborative environment to perform design \& manufacturing operations. Traditional Design processes have a one-way process that consists of four main phases: customer, market analysis, designer and manufacturing engineers followed in the same order where each phase was a standalone centralized system with minimum cross functional interaction. With the time technologies like CAD, internet services and client server model evolved drastically but overall the advantages provided by these systems were limited in nature as it was still following the same one-way methodology [3]. Moreover, there exists a rigid and costly system of supply chain till now whereas in Cloud-based Supply Chain, the supply chain is customer centric and the users with specific needs are linked with the service providers while meeting the cost, time and quality requirements of the user.

This is where adoption of Cloud Based Design and Manufacturing (CBDM) becomes essential as it is based on a cloud platform that allows users to collaborate and use the resources on demand and on a self-service basis. This provides flexibility and agility, which is required to reconfigure the resources to minimize the down-time, also called Rapid scalability. CBDM is designed to allow collaboration and communication between various actors involved from design to delivery phase in the crossdisciplinary teams to work in a collaborative way in real time from anywhere in the world with access to internet. Cloud manufacturing allows to produce variety of products of varying complexity and helps in mass customization. Using the CBDM system, the prototypes of the part can be manufactured without buying costly manufacturing equipment. Users can pay a subscription fee to acquire software licenses and use manufacturing equipment instead of purchasing them. Finally, usage of cloudbased environment leads to saving of opportunities as the tasks that were not economically viable earlier can be done using the cloud services. 


\section{State of The Art}

\subsection{Cloud Based Collaborative Atmosphere}

With the coming \& advancement of Web 2.0, social collaborative platforms provided a wonderful way to exchange information and data [4]. The internet based information and communication technologies are now allowing to exchange information in real time and are providing means to put into practice the concepts of mass collaboration, distributed design \& manufacturing processes [5]. Collaboration-based Design \& Manufacturing comprises all the activities that revolve around the manufacture of a product and leads to significant economies of scale, reduced time to market, improvement in quality, reduced costs etc. In a cloud manufacturing system, manufacturing resources \& capabilities, software etc. are interconnected to provide a pool of shared resources and services like Design as a Service, Simulation as a Service, and Fabrication as a Service to the consumers [6]. Current researches have emphasized a lot on the connectivity of products or in other words smart connected products via cloud environment for better collaboration of various operations of manufacturing being carried out on a product [7] and hence this acted as a first motivation of going into cloud domain for design and manufacturing. Also many larger scale enterprises have formed decentralized and complex network of their operations in the field of design and manufacturing where constant interaction with small scale enterprise is becoming a challenge. However, with the emergence of cloud computing there is an observation that more and more enterprises have shifted their work into cloud domain and have saved millions of dollars [8,9] and hence this forms our second motivation behind implementing manufacturing which in our case is AM on "Cloud" which is backed by the fact that the currently automobile and aeronautics giants have been shifting wide portion of their work into cloud platform by implementing cloud computing technology into many business lines pertaining to engineering domain. This also reaffirms our belief that cloud computing is envisaged to transform enterprise both small and big to profit from moving their design and manufacturing task into the cloud. Hence this forms the first pillar of the proposed CBDM.

\subsection{Rapid manufacturing scalability}

The idea of providing manufacturing services on the internet was in fact developed a long time ago when researchers envisaged the propagation of IOT (Internet of Things) in the production. Recent research has showcased the importance to have continuous process flow in lean product development which gave rise to an idea of having scalability in manufacturing process to have more liquidity in the manufacturing process.

In a world of rapid competition, scalability of rapid manufacturing is more important than ever. In the alignment to the statement made by Koren et al [10] regarding importance of reconfigurable manufacturing systems (RMSs) for quick adjustment in production capacity and functionality, CBDM allows users to purchase services like manufacturing equipment, software licences with reconfiguration module which in turns allow scalability of the manufacturing process and prevents 
over purchasing of computing and manufacturing capacities. This digital manufacturing productivity greatly enhances the scalability of the manufacturing capacity in comparison to the traditional manufacturing paradigm and this has been evident from the recent research work carried out by Lechevalier et al. [11] and Moones et al. [12] who have showcased efficient interoperability in a collaborative and dynamic manufacturing framework. As stated by Wua et al [13], from the perspective of manufacturing scalability, CBDM allows the product development team to leverage more cost-effective manufacturing services from global suppliers to rapidly scale up and down the manufacturing capacity during production. Hence, Rapid manufacturing scalability forms our second pillar of the proposed methodology.

\subsection{Design and additive manufacturing methodology model}

In this section, the flow of information in the digital chain has been studied to optimize the quality of AM which remains our focus in the experiment to test proposed methodology. This information management system interacts with the support infrastructure [14] (The standards, methods, techniques and software). The table whose phase 3 to 6 are represented in Fig. 1, provides an overview of the eight distinct stages and transitions. With a clear understanding of the various phases of additive manufacturing and transitions of information between each phase, we were able to identify optimization opportunities of additive manufacturing and establish mechanisms and tools to achieve them. In the current research phase 3 and 4 have been considered as represented by dotted line region in Fig. 1. This transition is an important preparedness activity to AM that is essential to the achievement of the final product [15]. It includes activities like journal of 3D model, generation of the carrier around the 3D model, decomposition in successive layers of a 3D model and generating a code which contains the manufacturing instructions for the machine. It is this transition stage "Activities for AM process" which is dealt later in this research project where AM process is optimized in the proposed methodology making this model a fourth pillar to the methodology.

\subsection{Real-Time Business Model}

One of the major advantages of using CBDM is that we are always linked to the outer world and this lets us know the real-time scenario. So as one of the pillars of our methodology we propose Real-time Business model to execute the entire process in the most efficient way in terms of quality and cost. The Real-Time Request for Quotation (RT-RFQ) is an interesting feature which increases the utility of the system. This basically utilizes the Knowledge Management System (KMS) which are an integral part of Cloud based design and manufacturing systems [16]. The selection of candidate KSPs is done based on the abilities and the capacities of the KSP to produce the product within stipulated time, cost and quality. 


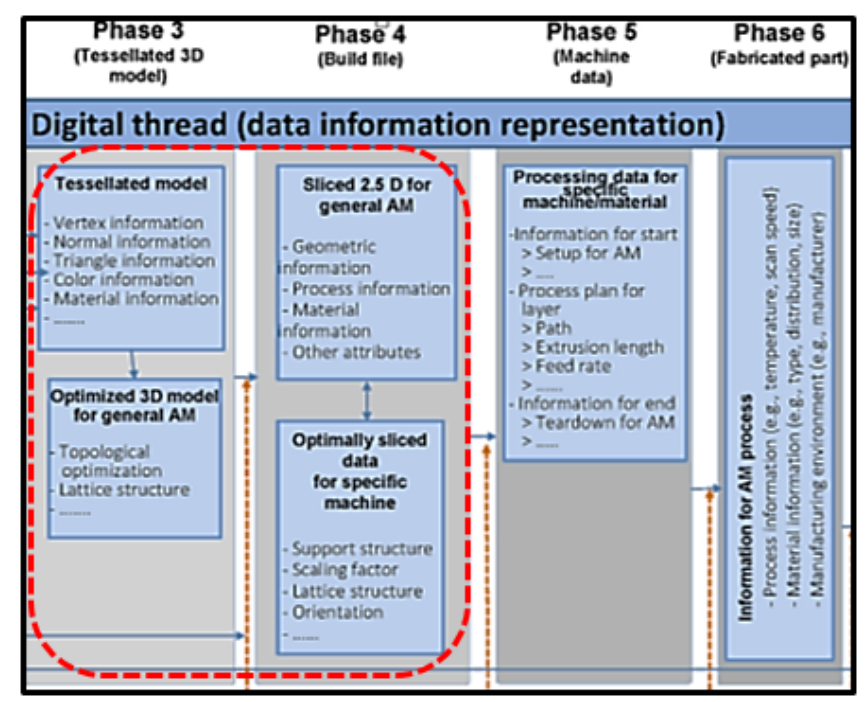

Fig. 1. Extract of digital channel Information flow for AM as proposed by Kim D [17]

The entire process of generating a request for quotation, finalising the service provider and delivery of the final product is in real-time thus creating collaboration between the sellers and the buyers, which we name it as "Market Place". The entire Material Management and the Supply Chain of the product in a collaborative platform is an integral part of our proposed methodology thus forming one of the pillars.

\section{Proposal of a methodology}

\subsection{Synthesis}

Synthesis of the proposed methodology is supported by four foundation pillars: Cloud environment, Rapid manufacturing scalability, Design and additive manufacturing methodology model and real-time business model. As discussed in the section 2.3, optimization process involved in AM workflow is rich in research opportunities and thus important to reduce the number phases involved in the manufacturing process. In the construction of methodology, a centralized system has been considered which controls all the process i.e. cloud domain and forms a platform where all actions will take place. Thus "Cloud" atmosphere forms heart of the methodology which starts with inputs that are decided during the RFQ and award acknowledgement process of a project. 3D design (phase-1) followed by two new functionalities such as Preparation for manufacturing (phase-2) and the Marketplace (phase-4). Then comes generic processes manufacturing (phase 4) which in combination with phase-1, phase-2 and phase-3 gives the power of rapid manufacturing scalability as discussed in the section 2.2. Last two phases represent packaging (phase-5) and delivery (phase-6) that constitutes the supply chain network of the process and are interconnected to phase- 3 "Mar- 
ketplace" in cloud by the means of interactions. Phase- 3 , phase- 5 and phase- 6 along with inputs given to the process is inspired form the real-time business model as discussed in the section 2.4. This way four pillars forms the backbone of the methodology. Collaboration at each phase in form of propagation of design, consultation, evaluation and notification happens in parallel or simultaneously during the process which forms a distributed and connected network in the methodology.

In addition to defining pillars, the existing methodologies workflow was simplified. The methodology process has been scaled down to six phases, instead of eight as mentioned by Kim D [17]. For that, some sub-stages were regrouped into phases to optimize the process and simplify the methodology Indeed, it was noticed that by reducing phases and regrouping linked sub-stages to a single phase, we can minimize the interactions that could happen during transitions between the different phases that aided us in achieving 6 phase methodology process with multiple parallel interactions. By grouping sub steps to main steps, we proposed a 6-phase methodology. This approach of grouping sub steps represents our idea of moving for a "task to do" vision to a "defined role" vision. Instead of thinking as a task of 3D scanning, 3D modelling or a triangulation together, it would be a better to think as a task of a function such as 3D designer or a mechanical engineer. Following this approach, we group several tasks to a specific role. That's how we simplified our methodology, which is checked and validated in the case study applied to AM.

\subsection{Methodology}

From the 3D design to the product delivery, this methodology describes six phases including five transitions with tractability on the cloud as outlined in the Fig. 2.

As shown on Fig. 2, the methodology process starts with a 3D design phase (1) which involves designing the product in a 3D environment, produce 3D CAD File and save it on the Cloud by allowing collaborative work with someone who has the access. This file is then sent to be prepared for manufacturing (2). A preparation of the 3D model before manufacturing is basically deciding the manufacturing process that will be used to produce the designed part. Sub steps such as repair geometry, meshing, weight optimization and finite elements simulations are grouped in a single manufacturing preparation phase (2). Once the file prepared for manufacturing, it's uploaded to a Marketplace (3) platform where the product will be evaluated and reviewed by service providers. It an online collaborative platform which brings together buyers (designers, engineers and product developers) and sellers the key service providers (KSPs) who manufacture and bring the design and the concept to realization. Here phase 2 and 3 works in parallel to double check whether the 3D file is ready for manufacturing or requires a further preparation or optimization for manufacturing process to be used. At this stage, the product design has been optimized, prepared for manufacturing and the most efficient service provider has been awarded the order by the designer. Those service providers will lead the customer to the appropriate manufacturing process and will start the manufacturing phase (4). A validation and evaluation product loop occurs after manufacturing to make sure the product matches the requirement specifications. Once the product is manufactured and validates the re- 
quirements, the service provider proceeds to the packaging (5) then the delivery (6). The service provider selected in the Market place also has the responsibility of providing packaging and delivery service.

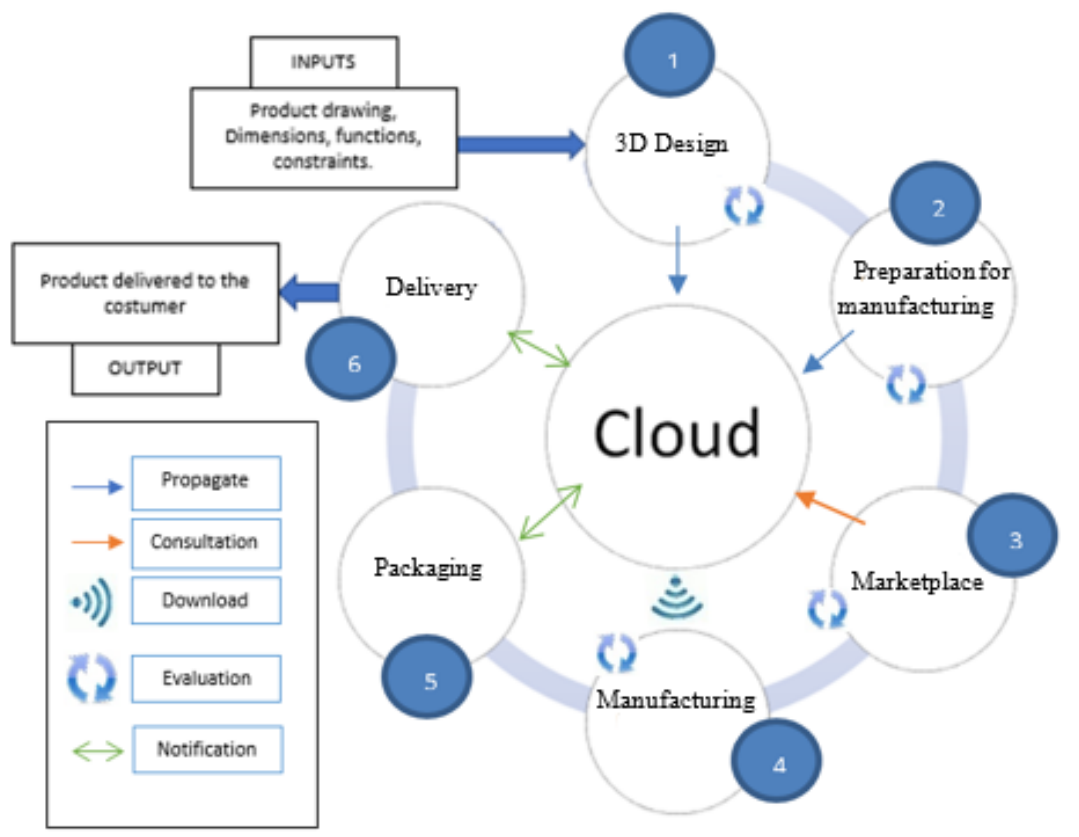

Fig. 2. Proposal of a CBDM methodology

The methodology proposed here, is the result of a conceptual and theoretical work. However, it must be applied at a practical level to evaluate its efficiency. We have implemented the proposed thermotical model on a case study to enlighten the benefits of this model in a real-world scenario. The following section describes a case study of the proposed methodology, applied to Additive Manufacturing.

\section{Case study: Additive Manufacturing}

This research is conducted in a partnership between the LCPI, a research lab in the Engineering School Arts et Métiers ParisTech, and Dassault Systèmes company. Collaborate to unify an academic research entity and an industrial Leader is one of our main purposes to point out merits of CBDM such as distributive \& collaborative network as a solution to today's design \& manufacturing activities. The proposed model in this paper, is tested by carrying out designing, manufacturing, trading on Marketplace and finally packaging for a very common industrial product called "joiner" in a collaborative \& distributed environment on a cloud platform to demonstrate the feasibility of the proposed solutions by experimental tests. 
Additive manufacturing (AM) has become a new way to realize objects from a 3D model [18] as it provides a cost-effective and time-efficient way to produce lowvolume, customized products with complex geometries and advanced material properties and functionalities.

From 3D design to product delivery, step by step the proposed methodology discussed in the section 3 has been applied in AM context and thus changing the step (2) from "Preparation for manufacturing" to "Preparation to Additive Manufacturing" and the rest remains the same. As the project was conducted in a partnership with Dassault Systèmes, and the fact that we want to use a unique platform for the whole CBDM process, the "3DEXPERIENCE" solution by enterprise was used to test the proposed methodology. The focus was on optimizing the methodology dataflow, which impacts directly the product quality.

\section{Step 1: 3D design}

In the first phase, the user will use a 3D design app on the cloud and work collaboratively. Once the product is designed and converted into an appropriate format, we proceed to the preparation process for manufacturing.

\section{Step 2: Preparation for manufacturing}

We have a $3 \mathrm{D}$ model file at this stage which requires preparation for the $3 \mathrm{D}$ printing. The Fig. 3 describes the fundamental AM processes and operations followed during preparation for manufacturing the CAD model in an AM environment. During the process Pre-context setting, Meshing were also carried out.

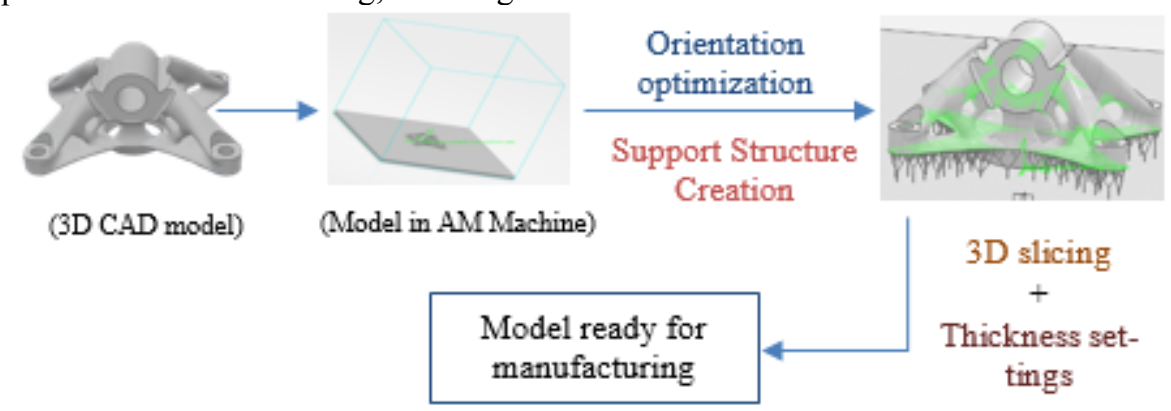

Fig. 3. Preparation for manufacturing steps

\section{Step 3: The 3DMarketplace}

The 3DMarketplace is a platform for additive manufacturing. It addresses the end-toend process of upstream material design, downstream manufacturing processes and testing to provide a single flow of data for engineering parameters. The objective here as a buyer is to select the most efficient key service provider possessing the required capabilities and skill sets on the Marketplace to proceed to the manufacturing phase (Fig. 4). The Marketplace shows up a list of service providers that can process the product manufacturing. A printing request was sent to the laboratory where a back and forth transition between the buyer and the service provider is necessary to make assure the printability of the $3 \mathrm{D}$ model and the use of the right manufacturing technology. This phase is done by confirmation of the order and starting of the AM process. 


\section{Step 4-5-6: Manufacturing, Packaging and delivery}

As defined in the proposed methodology section, the service provider from the Marketplace takes care of the manufacturing, packaging and delivery service. For the delivery, we chose to pick up the part. The customer can rate their experience and raise complaints on the 3DMarketPlace if required, and thus allowing improvement in the services provided.

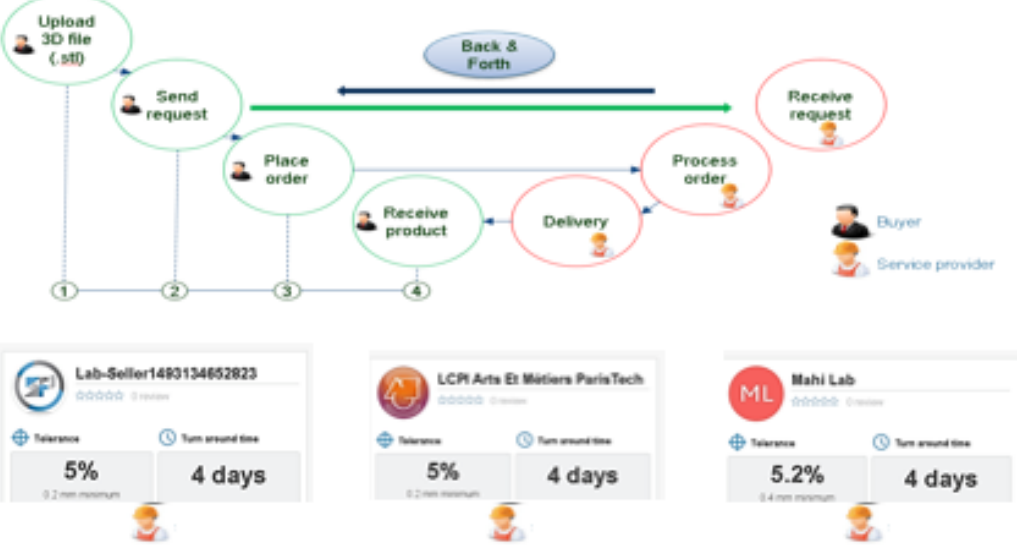

Fig. 4. The 3D Marketplace procees with used service providers during experiment

\section{$5 \quad$ Conclusion and Future work}

The successful implementation of Cloud based additive manufacturing demonstrated that Collaborative and distributed design and manufacturing task as complex as AM can be performed with ease by using cloud based service. This research points towards a centralized user interface i.e. cloud platform which forms the heart of the proposed methodology thus allowing its users to aggregate data and facilitate coordination, communication and collaboration among its various players of design, development, delivery and business segments.

We optimized the digital workflow while applying the proposed methodology, which helped in obtaining better quality products, shorter machining time, less material use and reduced AM costs. One of the main gains from study was the use of 3D mar-ket place in the methodology which offers a collaborative atmosphere for discussing subjects such 3D model design, geometry preparation and the appropriate manufacturing and also aides in the evaluation and validation of the two previous phases of the proposed methodology which is great from the outlook of the optimization and accuracy point of view in product development and delivery. The prototype of the CBDM system presented in this work will help to develop confidence in the functioning of a CBDM system especially in the domain of AM and will serve an ideal framework for developing it better for the near future.

Future work can consist of an adapted version of the proposed methodology CBAM (Cloud Based Additive Manufacturing) with more optimized process for AM. Overall the proposed methodology based on the work performed in the case study 
offers: a simplified, optimized, collaborative and AM applied solution that could be used in industrial and academic contexts and further strengthens the idea of adoption of cloud based services in the manufacturing sector soon.

\section{References}

1. Belkadi F, Kumar Gupta R, Vlachou E, Bernard A, Mourtis D (2016) Linking modular product structure to suppliers' selection through PLM approach: A Frugal innovation perspective, PLM'16 - IFIP 13th International Conference on PLM.

2. Boton C, Rivest L, Forgues D, Jupp J (2016) Comparing PLM and BIM from the Product Structure Standpoint, PLM'16 - IFIP 13th International Conference on PLM.

3. Abadi, D. (2009), "Data Management in the Cloud: Limitations and Opportunities", IEEE Data Eng. Bull 01/2009; 32(1, article 312):3-12.

4. Wu D, Schaefer D, Rosen D (2013) "Cloud-based design and manufacturing systems: A social network analysis", Proc. International Conference on Engineering Design (ICED13)

5. Schaefer D, Thames J, Wellman R, Wu D (2012) "Distributed Collaborative Design and Manufacture in the Cloud-Motivation, Infrastructure, and Education", ASEE.

6. Ren L, Zhang L, Tao F, Zhao C, Chai X, Zhao X (2015) "Cloud manufacturing: From concept to practice", Enterprise Information Systems, 9:2, 186-209

7. Goto S, Trolio E, Yoshie O, and Tamaki K (2016) Multi-party Interactive Visioneering Workshop for Smart Connected Products in Global Manufacturing Industry Considering PLM, PLM'16 - IFIP 13th International Conference on PLM.

8. Wu, D., Rosen, D. W., and Schaefer, D., 2014, "Cloud-based design and manufacturing: Status and promise," a service-oriented product development paradigm for the 21 st century, Springer, London, UK, ISBN 978-3-319-07398-9, pp. 1-24.

9. Wu, D., Rosen, D. W., Wang, L., and Schaefer, D., 2014, "Cloud-based manufacturing: old wine in new bottles?," Proceedings of the 47th CIRP Conference on Manufacturing Systems, Windsor, Canada, pp. 94-99.

10. Yoram K, Moshe S (2010) Design of Reconfigurable Manufacturing Systems. Journal of Manufacturing Systems, 29, 130-141.

11. Lechevalier D, Narayanan A, Rachuri S, Foufou S, Lee T (2016) Model-based Engineering for the Integration of Manufacturing Systems with Advanced Analytics. PLM'16 - IFIP 13th International Conference on PLM.

12. Moones E, El Mouloudi D, El Mhamedi A, Figay N, Koudri A (2016) Interoperability improvement in a collaborative Dynamic Manufacturing Network. PLM'16 - IFIP 13th International Conference on PLM.

13. Wua D, Rosena D, Wangb L, Schaefer D (2015) Cloud-based design and manufacturing: A new paradigm in digital manufacturing and design innovation, CAD 59 (2015) 1-14

14. Kim, DB, Witherell, P. Lipman, R., \& Feng, SC (2015). Streamlining the additive manufacturing digital spectrum: A systems approach. Additive manufacturing, 5 20-30

15. Fenves, S. A core product model for representing design information. 2001. National Institute of Standards and Technology: Gaithersburg, MD.

16. Li, Y., Linke, B. S., Voet, H., Falk, B., Schmitt, R., \& Lam, M. (2017). Cost, sustainability and surface roughness quality-A comprehensive analysis of products made with personal 3D printers. CIRP Journal of Manufacturing Science and Technology, 16, 1-11.

17. Kim, DB, Witherell, P. Lipman, R., \& Feng, SC (2015). Streamlining the additive manufacturing digital spectrum: A systems approach. Additive manufacturing, 5 20-30

18. Thompson, M. et al. (2016). Design for Additive Manufacturing: Trends, opportunities, considerations, and constraints. CIRP Annals-Manufacturing Technology, 65(2), 737-760. 